\title{
塩化鉄を利用するニッケルコバルト混合硫化物の塩素浸出
}

\author{
小林宙庄司浩史浅野聡今村正樹
}

住友金属鉱山株式会社新居浜研究所

J. Japan Inst. Met. Mater. Vol. 81, No. 5 (2017), pp. 282-287

(C) 2017 The Japan Institute of Metals and Materials

\section{Chlorine Leaching of Nickel and Cobalt Mixed Sulfide using Iron Chloride Solution}

Hiroshi Kobayashi, Hirofumi Shoji, Satoshi Asano and Masaki Imamura

NIIHAMA RESEARCH LABORATORIES, SUMITOMO METAL MINING CO., LTD., Niihama 792-0002

The matte chlorine leach and electro-winning (MCLE) process, developed by Sumitomo Metal Mining Co., Ltd. (SMM) is well known as a unique commercial nickel refining process with a high nickel recovery ratio. SMM has gradually increased the ratio of mixed sulfide (MS: mixture of nickel and cobalt sulfides) that can be used as a raw material in the MCLE process over the past decade. However, the reactivity of MS in chlorine leaching remains insufficient and further improvements are needed.

We performed bench scale chlorine leaching tests with iron chloride, instead of the currently used copper chloride, as an oxidant medium for chlorine gas. However the reactivity of MS was not improved despite the higher oxidation-reduction potential (ORP) of iron chloride than that of copper chloride. Though stability studies of iron chloride complexes based on an E-pCl (potential, $-\log \mathrm{a}_{\mathrm{Cl}}{ }^{-}$) diagram, the chlorine leaching potential that is suitable for copper chloride was found to be too low for iron chloride. Reactivity of MS was improved at a higher leaching potentials; however this did not represent a significant improvement over copper chloride based methods. We elucidated the reaction mechanism and showed that chlorine leaching with iron chloride is not suitable for industrial application to MS. [doi:10.2320/jinstmet.J2016065]

(Received November 21, 2016; Accepted February 24, 2017; Published April 25, 2017)

Keywords: mixed sulfide, chlorine leaching, iron chloride, oxidation-reduction potential (ORP), potential diagram (E-pCl)

\section{1. 緒 論}

現在, ニッケルの商業生産では, ニッケル硫化鉱および ニッケル酸化鉱を一次精錬 (濃縮) して得られるニッケルマッ ト $\left(\mathrm{Ni}_{3} \mathrm{~S}_{2}\right.$ : 金属ニッケルと硫化ニッケルの混合硫化物 $)$ および ニッケルコバルト混合硫化物 (Mixed Sulfide : 以下 MS) を出 発原料とする湿式精錬法が主流となっており, 世界各地で本 法による精鍊が行われている.

この精錬に用いるニッケル硫化物原料の種類としては, 次 第に世界のニッケル硫化鉱の生産量が減少していることと, 中国を筆頭とした新興国による旺盛な消費を受けて，同鉱石 を精錬して得られるニッケルマットを市場から有利な条件で 入手しにくくなっており, 熱帯および亜熱帯に豊富に賦存す るニッケル酸化鉱を湿式精錬して得られる MS を湿式精錬の 主要原料とすることが望まれる状況となっている.

前記ニッケル湿式精錬法の一例としてニッケル硫化物の塩 素浸出, 電解採取 (Matte Chlorine Leach and Electro-winning, 以下 MCLE) プロセスが知られている. 本方法は高い生 産性を有するニッケル精錬方法1)であるが，その根幹となる 塩素浸出工程における MS の浸出速度は既報2)の通り, マッ トと MS の組織構造差と反応ポテンシャルの差により, ニッ ケルマットの $40 \%$ と著しく小さいということが判明しており, このような反応性の低い MS を高速に塩素浸出処理する新し い技術の展開とその確立が求められている。

本報告はニッケル硫化物のうち MS を原料とした場合の塩
素浸出反応機構について解析したものである. 具体的には MS の塩素浸出において, 反応水溶液中における塩素ガスによる 酸化還元対 $\mathrm{Cl}_{2} / \mathrm{Cl}^{-}$の酸化反応を塩化銅の酸化還元対 $\mathrm{Cu}^{2+} /$ $\mathrm{Cu}^{+}$を間接的な $\mathrm{Cl}$ 供給媒体とする場合 (MCLE 工程で採用, 操業中) と, より有利に浸出できる可能性のある塩化鉄の酸化 還元対 $\mathrm{Fe}^{3+} / \mathrm{Fe}^{2+}$ を間接的な $\mathrm{Cl}$ 供給媒体とする場合について 比較し, 塩化鉄による塩素浸出の可能性とそのメカニズムに ついて研究した.

なお, 本報告ではこの酸化還元対 $\left(\mathrm{Cl}_{2} / \mathrm{Cl}^{-}\right)$による間接的な 酸化を進行させる酸化還元対 $\mathrm{Cu}^{2+} / \mathrm{Cu}^{+}$の基となる塩化銅, あるいは酸化還元対 $\mathrm{Fe}^{3+} / \mathrm{Fe}^{2+}$ を基となる塩化鉄を塩素浸出 媒体 (以下, 媒体)と表現することとする.

上記, MCLE工程で採用されている塩化銅を用いる MS 中 のニッケルの塩素浸出反応は下記対となる酸化還元反応式 (1), ( 2 ) から構成される2).

$$
\begin{gathered}
2 \mathrm{Cu}^{+}+\mathrm{Cl}_{2}=2 \mathrm{Cu}^{2+}+2 \mathrm{Cl}^{-} \\
\mathrm{NiS}+2 \mathrm{Cu}^{2+}=\mathrm{Ni}^{2+}+2 \mathrm{Cu}^{+}+\mathrm{S}^{0}
\end{gathered}
$$

式 (1) は塩化物水溶液中で 1 価の銅イオンが塩素にて酸化 される形で水溶液中に塩素を吸収する酸化還元反応, 式 (2) は式 (1)で生じる酸化された 2 価銅イオンが硫化ニッケル中 の硫化物イオンを元素硫黄まで酸化させると同時に, ニッケ ルを塩化ニッケルとして浸出, 反応に寄与した 2 価銅イオン は還元される反応である.これら 2 式が対となり, 銅イオン の酸化還元対が塩素の酸化還元対の媒体として機能する.こ の反応において塩素は直接ニッケルの浸出に寄与せず, 銅イ オンが媒体として働く水溶液中で塩素ガスは強い酸化作用を 
持つが，媒体を介することで緩和される。この緩和効果より， ニッケルの浸出を促進させながら, 硫化物イオンの酸化を元 素硫黄までに留めることが可能となる，このように，媒体の 利用により間接的に硫化物イオンの酸化を進行させ元素硫黄 までに酸化を抑制することは工業的に大変重要である。これ は電解採取によるニッケルカソードの生産を行う MCLE プロ セスにおいて, 硫化物精錬より副産物として元素硫黄の回収 を可能とし, 同時に浸出工程の後段にある塩化ニッケルから のニッケル電解採取工程において硫酸イオンの増加による導 電率の悪化 ${ }^{3)}$ を抑制し，電解電圧を低く維持をすることがで きるからである。

一方， ニッケル浸出反応が進行して浸出残椬中の元素硫黄 の比率が上昇してくると, 上記反応以外に式 ( 3 )の元素硫黄 が硫酸イオンまで酸化される反応も進む.

$$
\mathrm{S}+4 \mathrm{H}_{2} \mathrm{O}+6 \mathrm{Cu}^{2+}=\mathrm{H}_{2} \mathrm{SO}_{4}+6 \mathrm{Cu}^{+}+6 \mathrm{H}^{+}
$$

生成した硫酸は系内液を中和処理することにより定期的に 系外へ払い出すことが必要となるため, コストを上昇させる ことになり好ましくない.このため, 上記のような硫黄の酸 化抑制は非常に重要な技術要素である。本報告では MS 中の 硫黄分(硫化物イオン)が反応によって生成される元素硫黄を 経て硫酸イオンまで酸化される比率を塩素浸出反応における 硫黄酸化率 (以下, 硫黄酸化率) と定義した。

塩化銅同様に, 塩化鉄も式 (4), 式 ( 5 )の対の反応を介し て塩素浸出反応の媒体となると考えられる.

$$
\begin{gathered}
2 \mathrm{Fe}^{2+}+\mathrm{Cl}_{2}=2 \mathrm{Fe}^{3+}+2 \mathrm{Cl}^{-} \\
\mathrm{NiS}+2 \mathrm{Fe}^{3+}=\mathrm{Ni}^{2+}+2 \mathrm{Fe}^{2+}+\mathrm{S}^{0}
\end{gathered}
$$

式 ( 5 ) に寄与する酸化還元対 $\mathrm{Fe}^{3+} / \mathrm{Fe}^{2+}$ の酸化還元電位は式 （2）に寄与する酸化還元対 $\mathrm{Cu}^{2+} / \mathrm{Cu}^{+}$よりも $0.62 \mathrm{~V}$ 高いため ${ }^{4)}$, 塩化鉄を媒体として用いると塩化銅よりも反応速度が上昇し て, 反応の効率が高められる可能性がある. そのため, 塩化鉄 を媒体として用いた際の MS からのニッケルの塩素浸出挙動を 解明することは，同法を用いた塩素浸出処理の工業適用可能性 判断において重要であると考え，本研究にて取り組んだ。 な お, 酸性領域にて形成されうる酸化還元対としては $\mathrm{Co}^{3+} / \mathrm{Co}^{2+}$ もあるが, これは酸化還元電位が塩素の酸化還元対電位よりも 高く，媒体として機能しないため対象から除外した.

また, この反応でもニッケルの浸出反応が進み, 浸出残椬 中の元素硫黄比率が上昇してくると式 ( 6 )の元素硫黄を酸化 させる反応も進行するため, 硫黄酸化の抑制ついての知見を 得る意義は高い.

$$
\mathrm{S}+4 \mathrm{H}_{2} \mathrm{O}+6 \mathrm{Fe}^{3+}=\mathrm{H}_{2} \mathrm{SO}_{4}+6 \mathrm{Fe}^{2+}+6 \mathrm{H}^{+}
$$

本研究では両媒体による MS の塩素浸出反応の差を明らか にすることを目的とする．なお，塩化鉄を媒体として用いる 塩素浸出方法はフランスの Eramet 社にて操業中であるが, 対 象原料はニッケルマットとフェロニッケル5)であり， MSへの 適用可否, 詳細な浸出条件については公開されていない.

\section{2. 試料と試験方法}

\section{1 試料}

塩素浸出試験に用いた MS はコーラルベイニッケルコーポ レーション社 (Coral Bay Nickel Corporation) 産出物 ${ }^{6)}$ である.
Table 1 に試験に用いた化合物組成を示す。この組成は ICP による各元素の化学分析值と XRD 分析結果から, 化学等量計 算を行って求めたものである. XRD 分析により認められた硫 化物は硫化ニッケルとしては $\mathrm{NiS} と \mathrm{Ni}_{3} \mathrm{~S}_{4}$ であった. 残りの 硫化物は硫化コバルト $(\mathrm{CoS})$ と硫化鉄 $(\mathrm{FeS})$ であった，MS は 粉砕し, D50粒径が $50 \mu \mathrm{m}$ となるように篩により粒度調整し て用いた。

塩素浸出媒体には和光純薬工業株式会社製の塩化鉄 (III) 六 水和物 (試薬 1 級, 含量 : $99 \%$ ), 塩化銅 (II )二水和物 (試薬特 級, 含量：99\%)を用いた。

\section{2 塩素浸出反応とその評価法}

本研究の目的は塩素浸出媒体による MS からのニッケル浸 出機構確認である.

\subsection{1 酸化剂の反応速度試験}

最初に酸化剂である塩化銅 (II ) および塩化鉄 (III) と MS を 反応させ，式 (2)，および式 (5)に相当するそれぞれの酸化 片によるニッケル浸出速度を求めた。この速度は MS を塩化 銅 (II) または塩化鉄 (III) 水溶液に混合攪拌し， 反応をさせる ことで評価した，反応容器としては $1 \mathrm{~L}$ の蓋付きセパラブル フラスコを利用し，オイルバスにて一定温度に維持した．塩 化銅 (II) と塩化鉄 (III) はそれぞれ純水に溶解し水溶液として 利用した. MS と塩化鉄 (III)，および塩化銅 (II ) 水溶液の混 合比率は，それぞれ MS 中のニッケル量に対して，酸化剂不 足とならないことを前提とし，塩化鉄 $($ III $)$, および塩化銅 （II）の量は MS 試料中のニッケル量に対して mol 比で100倍 とした. 水溶液の中の塩化物イオン濃度は塩酸にて $2.0 \mathrm{kmol} /$ $\mathrm{m}^{3}$ となるように調製した。 反応温度は $100^{\circ} \mathrm{C}$, 反応時間は 7.2 $\mathrm{ks}(2 \mathrm{~h})$ とした.

\subsection{2 塩素浸出試験}

次に, 酸化還元電位 (以下, ORP) 制御にて塩素ガスを特定 の ORPまで吹き込む塩素浸出反応における MSからのニッケ ル浸出速度を求めた．MS を塩素浸出反応の媒体である塩化 鉄 (III) または塩化銅 (II ) を含む塩化ニッケル水溶液中に攪拌 により分散させ，そのスラリーを塩素ガスにて特定の制御 ORPに維持した。なお，本報告では ORPの単位は銀／塩化 銀を基準とする電位とし, 以降, $\mathrm{vs} \mathrm{Ag} / \mathrm{AgCl}$ を省略して電位 を表記する．Fig. 1 に塩素浸出試験装置の略図を示す．反応 容器には $1 \mathrm{~L}$ の蓋付きセパラブルフラスコを利用し, オイル バスにて一定温度に維持した。

反応始液は濃度 $1.1 \mathrm{kmol} / \mathrm{m}^{3}$ となるように調製した塩化 ニッケル (II) 水溶液中へ塩化銅 (II ) および塩化鉄 (III) を混合, 溶解し, 塩素浸出媒体の濃度が $0.7 \mathrm{kmol} / \mathrm{m}^{3}, \mathrm{pH}$ は 1.0 となる ように調整した。上記調製した塩化ニッケル $($ II $)$ 水溶液の中 に MS $100 \mathrm{~kg} / \mathrm{m}^{3}$ の濃度でスラリー化, 制御 ORP を530$700 \mathrm{mV}$ の範囲に設定し, 塩素吹込み速度 $4.2 \times 10^{-5} \mathrm{~mol} / \mathrm{s}$ に て反応を進めた。

Table 1 Compound compositions of MS.

\begin{tabular}{cccc}
\hline $\mathrm{NiS}$ & $\mathrm{Ni}_{3} \mathrm{~S}_{4}$ & $\mathrm{CoS}$ & $\mathrm{FeS}$ \\
\hline 81.6 & 7.3 & 7.8 & 1.3 \\
\hline
\end{tabular}


反応温度は $100^{\circ} \mathrm{C}$, 反応時間は最大 $28.8 \mathrm{ks}(8 \mathrm{~h})$ とした。

\section{2 .3 分析評価}

反応開始以降，一定時間経過毎に浸出スラリーの一部を採 取し, ADVANTEC 社製 No. 5C 定量ろ紙にてろ過した. 固形 分は希塩酸を用いて十分に洗浄, 乾燥後, ニッケル, コバル トを定量分析し, MSからのニッケル, コバルト浸出率を求 めた。また水溶液中の硫酸イオン濃度の分析により，MS 浸 出残椬中の硫黄酸化率を測定した。分析装置としてはSIIナ ノテクノロジー社製の ICP 発光分析 (ICP-AES) 装置 ARCOS FHS12を用いた。

\section{3. 結果と考察}

\section{1 浸出反応}

\section{1 .1 酸化剂の反応速度}

塩化鉄 $($ III ) および塩化銅 (II) と MS との反応試験結果を

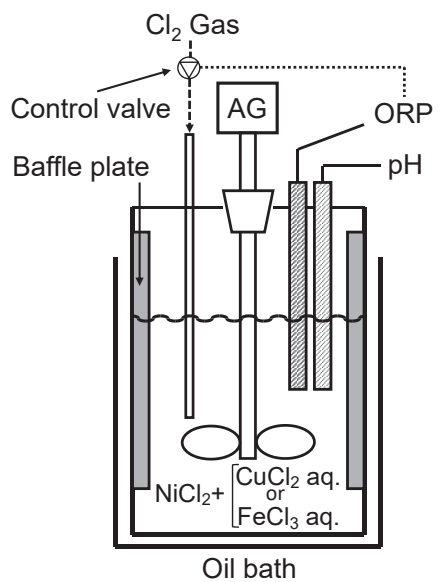

Fig. 1 Schematic diagram of a chlorine leaching reactor.

(a)

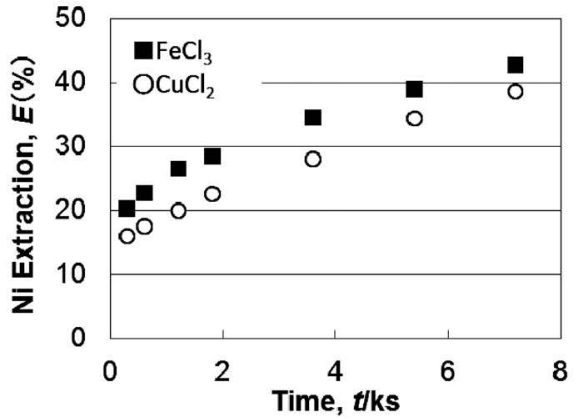

Fig. 2(a)に示す。Fig. 2(a)よりニッケル浸出率プロファイル は塩化鉄 $($ III ) と塩化銅 $($ II $)$ との酸化還元電位の差から期待さ れた通り僅かに塩化鉄 (II )の方が上回るという浸出挙動を示 した。

Fig. 2(b)には式（ 7 ）に示される Janderの式，時間に対する $\left(1-(1-\alpha)^{1 / 3}\right)^{2}$ の関係を示した。 これは既報 ${ }^{2)}$ のおり塩化銅 （II）を用いた時の MS の塩素浸出反応が生成層内拡散律速で あったことによる。

$$
\left(1-(1-\alpha)^{1 / 3}\right)^{2}=K \cdot t
$$

ただし， $\alpha$ : ニッケル浸出率, $K$ : 反応速度定数 $\left(\mathrm{s}^{-1}\right), t$ : 時 間 $(\mathrm{s})$

Fig. 2(b)における Janderの式との相関係数はいずれも高 く, 塩化鉄 $($ III ) も塩化銅 (II ) と同様に反応は生成層内拡散律 速と判断できる。 反応速度定数 $(K)$ を表すプロットの傾きは 塩化鉄 (III) が $0.0034 \mathrm{~s}^{-1}$ ，塩化銅 (II ) が $0.0028 \mathrm{~s}^{-1}$ であった.

これらの結果より, MSの塩素浸出において塩化鉄と塩化 銅との比較において塩化鉄のニッケル浸出速度が若干，大き くなる可能性が考えられる。なお，これら酸化㓮媒体自体と MS の反応速度を酸化剂の反応速度とした。

\section{1 .2 塩素浸出試験}

次に, これら塩素浸出媒体を塩化銅および塩化鉄とした場 合の MS の塩素浸出試験結果を Fig. 3(a)，Fig. 3(b)に時間に 対する塩素消費量の関係として示す．Fig. 3(a), Fig. 3(b)の 塩素浸出反応の制御 ORP はそれぞれ $530 \mathrm{mV}$ および $560 \mathrm{mV}$ とした。これらの制御 ORPを選択した理由は塩化銅を媒体と した塩素浸出において, 硫化ニッケル中の硫化物イオンを元 素硫黄まで酸化させ, 元素硫黄から硫酸までの酸化を抑制で きる反応条件 ${ }^{7}$ であることが判明しているからである.

いずれの制御 ORPにおいても，媒体として塩化鉄を用いた 方が，塩化銅を用いた場合に比べ，式(1), 式 (4)で示され

(b)

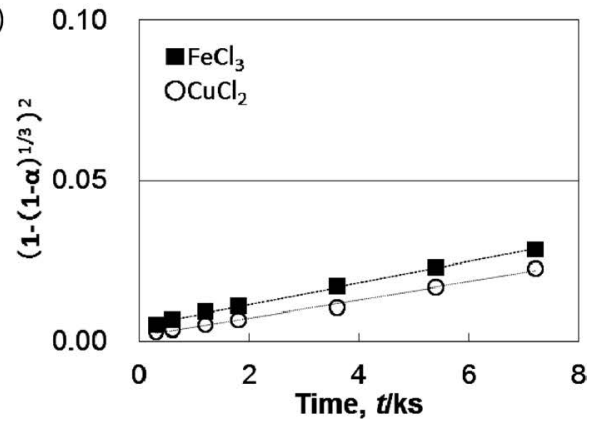

Fig. 2 Reactivity comparison of leaching reagents in MS chlorine leaching tests. (a) Extraction curves and (b) $\left(1-(1-\alpha)^{1 / 3}\right)^{2}$ vs time plots.

(a)

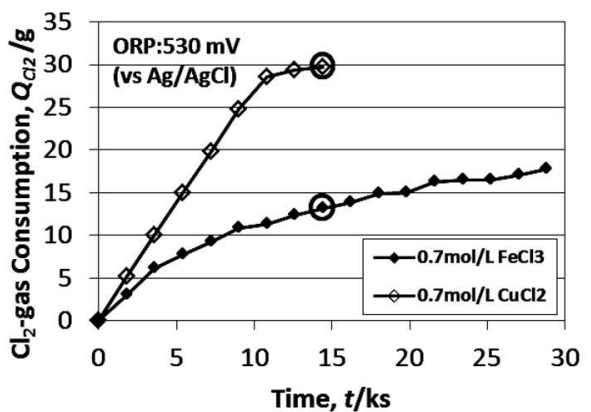

(b)

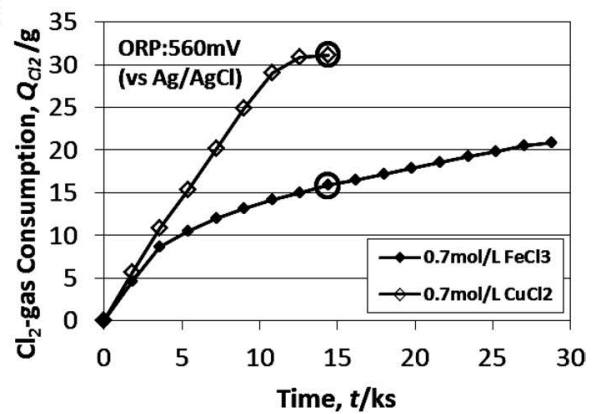

Fig. 3 Chlorine gas consumption curves in MS chlorine leaching tests under controlling ORP at (a) $530 \mathrm{mV}$ and (b) $560 \mathrm{mV}$ (vs Ag/ $\mathrm{AgCl}$ ) 
るように塩素ガス消費量が小さい。これは同一の制御 ORP下 では, 塩化鉄を用いたニッケルの塩素浸出速度の方が低いこ とを示している. Table 2 に反応 $14.4 \mathrm{ks}(4 \mathrm{~h})$ 後の MS からの ニッケル，コバルト浸出率と MS 中の硫黄酸化率を示す。制 御 ORP $530 \mathrm{mV}$ でのニッケルおよびコバルトの浸出率結果は 塩化鉄利用の場合，それぞれ $44.8 \%, 45.7 \%$, 塩化銅利用の場 合の $90.1 \%, 89.5 \%$ との比較で約 $50 \%$ 程度の浸出率となった. ニッケルとコバルトの浸出率は各条件において, ほぼ同等で あったが，これはイオン化傾向が近い4)ためである，また，硫 黄酸化率は塩化鉄では ORP $530 \mathrm{mV}$ のとき $0.8 \%$, ORP 560 $\mathrm{mV}$ のとき $4.2 \%$ に対し塩化銅では $5.8 \%, 8.4 \%$ であり，塩化鉄 の方が小さい值となった.

このように媒体を塩化鉄として, 塩素ガスの ORP 制御にて 塩素浸出をさせた場合に塩化銅と比べて塩素ガス消費速度, ニッケルおよびコバルト浸出率の低下が見られ, 塩素浸出反 応速度が低下した. Fig. 2 に示した塩化鉄 (III), 塩化銅 (II) の酸化剤の反応速度比較において塩化鉄 (III)の方がより高速 であったことから, 塩素浸出反応においては硫化ニッケルと 媒体との反応機構に違いがあると考えられる。 そこで, この ニッケル浸出反応機構の差について検証を実施した.

\section{2 ニッケル浸出反応機構}

\section{2 .1 酸化剂となるイオン種の不足}

媒体で MS からのニッケル浸出反応速度に差が生じる原因 として，媒体であるイオン種の量の不足の可能性につき検討 した.この検討の前に塩素浸出媒体となる塩化鉄および塩化 銅の錯安定度定数 ${ }^{8-11)}$ を参照し, $\mathrm{Fe}-\mathrm{Cl}-\mathrm{H}_{2} \mathrm{O}$ 系および $\mathrm{Cu}-\mathrm{Cl}-$ $\mathrm{H}_{2} \mathrm{O}$ 系の電位 $-\mathrm{pCl}$ 図をそれぞれ Fig. $4(\mathrm{a})$, Fig. 4(b) として 作成した. 両図の横軸の $\mathrm{pCl}$ は塩化物イオンの活量 $\mathrm{a}_{\mathrm{Cl}}{ }^{-}$の負

Table 2 Elements extraction ratio of MS chlorine leaching in the case of medium difference. $(4 \mathrm{~h})$

\begin{tabular}{|c|c|c|c|c|}
\hline \multirow{2}{*}{ Chlorine-leaching reaction } & \multirow{2}{*}{ ORP } & \multicolumn{3}{|c|}{ Leaching ratio } \\
\hline & & $\mathrm{Ni}$ & Co & $\mathrm{S}^{*}$ \\
\hline NiS / Di-chloro Copper ( II ) & \multirow{2}{*}{$530 \mathrm{mV}$} & 90.1 & 89.5 & 5.8 \\
\hline NiS / Tri-chloro Iron ( III) & & 44.8 & 45.7 & 0.8 \\
\hline NiS / Di-chloro Copper ( II ) & \multirow{2}{*}{$560 \mathrm{mV}$} & 97.5 & 89.2 & 8.4 \\
\hline NiS / Tri-chloro Iron ( III ) & & 47.3 & 48.0 & 4.2 \\
\hline
\end{tabular}

* $\mathrm{SO}_{4}{ }^{2-}$ (produced by MS oxidation )/ total S in MS

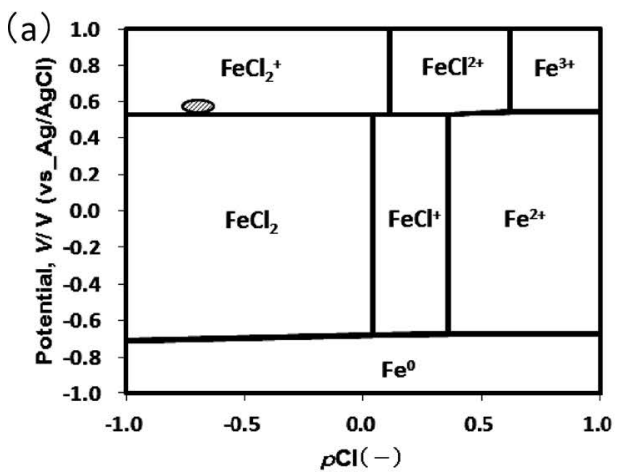

の常用対数 $\left(-\log \mathrm{a}_{\mathrm{Cl}}^{-}\right)$とした. $\mathrm{Cu}$ および $\mathrm{Fe}$ イオン種の活量 は0.5として計算した。 今回, 塩素浸出試験を実施した反応条 件は制御 ORP が 530-560 mV, pCl は塩素浸出試験条件では 塩素イオン濃度が $5-6 \mathrm{kmol} / \mathrm{m}^{3}$ となるため, -0.7 近傍であり, Fig. 4(a), (b) 中の斜線部分に相当する. この図より塩素浸出 反応中は, それぞれ $\left[\mathrm{FeCl}_{2}{ }^{+}\right],\left[\mathrm{CuCl}_{2}\right]$ の 2 価銅錯体, 3 価 鉄錯体が媒体として優位に存在していると考えられる。媒体 として塩化鉄利用の観点から Fig. 4(a) と Fig. 4(b) を比較する と, 塩化鉄の場合, 本塩素浸出反応の制御 ORP 領域は 2 価, 3 価形態の境界線近傍にあり, 実際の状態と平衡值とのズレ により仮説の酸化剂となるイオン種の量が不足した可能性を 否定できないことがわかる.

そこで，この図を参考に酸化剂となるイオン種である $\left[\mathrm{FeCl}_{2}{ }^{+}\right]$の量を増加させた試験を行った．試験は 2.2 .2 と同じ やり方で塩化鉄を媒体とする反応の制御 ORPを $700 \mathrm{mV}$ まで 約 $50 \mathrm{mV}$ 刻みで上昇させた. Fig. 5 に浸出の塩素ガス消費量 プロファイルを示す.この図には本試験共通の塩素吹込み速 度および $560 \mathrm{mV}, 600 \mathrm{mV}$ の制御 ORP が安定してからの塩 素吹込み速度の傾きを浸出反応速度の指標として併記した。 同ガス消費量の相対比率を Table 3 に, 浸出結果を Table 4 に 示す.

制御 ORP を上昇させたことにより，600，650および 700 $\mathrm{mV}$ の塩素消費量は塩化銅を媒体とした $560 \mathrm{mV}$ 条件を基準 として $65 \%, 97 \%, 110 \%$ と増加したが，ニッケル浸出率はそ れぞれ，51.0\%，54.7\%，63.8\%と微増にとどまり，塩化銅の

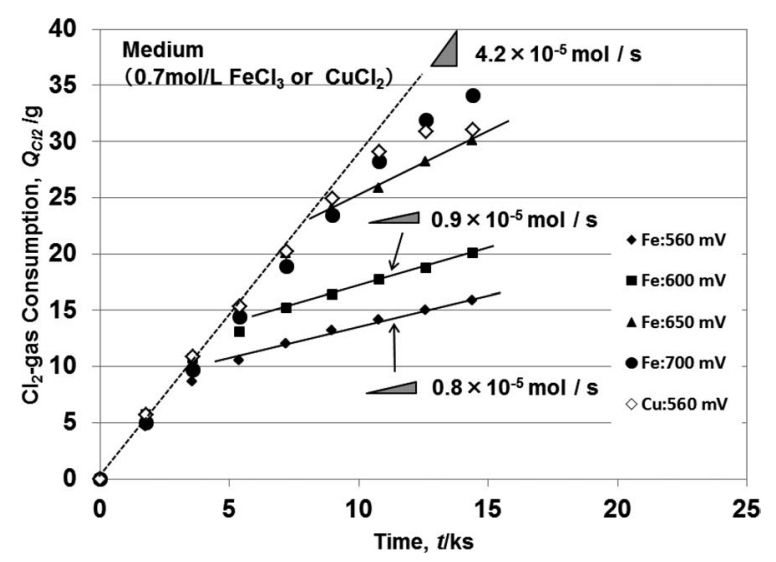

Fig. 5 Chlorine gas consumption curves of MS chlorine leaching using iron chloride at various ORP.

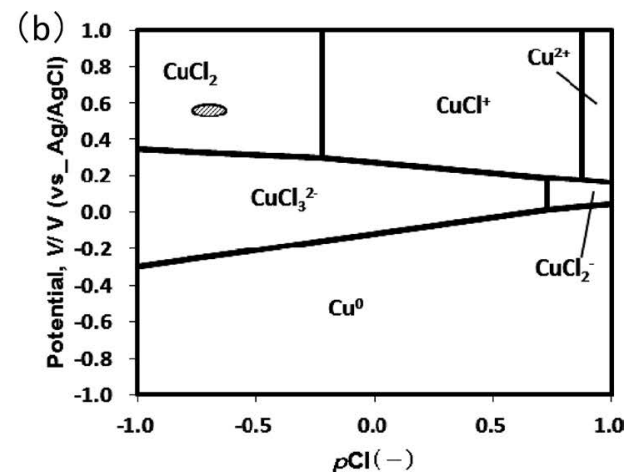

Fig. 4 Eh-pCl diagram of the (a) $\mathrm{Fe}$ ( II ) $-\mathrm{Fe}($ III $)-\mathrm{Cl}-\mathrm{H}_{2} \mathrm{O}$ system and (b) $\mathrm{Cu}(\mathrm{I})-\mathrm{Cu}$ ( II ) $-\mathrm{Cl}^{-} \mathrm{H}_{2} \mathrm{O}$ system at $297 \mathrm{~K}$. (All soluble $\mathrm{Cu}$ and $\mathrm{Fe}$ species are assumed to have activity of 0.5 ) 
場合の $97.5 \%$ を回った。このように塩素ガス消費量とニッ ケル浸出率が乘離していることから, 制御 ORPの上昇により 増加した塩素ガスが消費される内訳を成分毎の浸出率と塩素 ガス消費量から求め, Fig. 6 に塩化銅と比較として示す。こ こで塩素ガス消費の内訳は，ニッケル，コバルト，鉄の浸出 量と元素硫黄の酸化量から算出した. 塩素消費量の過剩分は 吸収されずに塩素ガスとして系外にロスするとした。なお， 過剩分を塩素ガスのロスとした理由は本塩素浸出試験の $\mathrm{pH}=$ 1 近傍の酸性かつ, $1000 \mathrm{mV}$ までの ORP 領域では次亜塩素 酸等のより酸化力のある過酸化物は液中に形成されない4) いう知見を考慮したためである.

この図より塩化鉄を媒体とした場合, 制御 ORP が $600 \mathrm{mV}$ までの範囲においては塩素のロスなく式 (4)から式 ( 6 )の反 応が進み, 酸化剂となるイオン種である $\left[\mathrm{FeCl}_{2}{ }^{+}\right]$の量の増加 による反応の促進効果が確認できる。 その反応速度は Fig. 5 の塩素ガス吹込み速度の傾きで示されるが，塩化銅媒体の 560 $\mathrm{mV}$ 条件では反応終盤まで塩素ガス吹込み速度である $4.2 \times$ $10^{-5} \mathrm{~mol} / \mathrm{s}$ に対応した速度であることに対し，塩化鉄媒体の

Table 3 Chlorine gas consumption in MS chlorine leaching. ( $4 \mathrm{~h}$ )

\begin{tabular}{ccc}
\hline Chlorine-leaching reaction & $\mathrm{ORP}$ & $\mathrm{Cl}_{2}$ gas consumption ratio* \\
\hline NiS / Di-chloro Copper( II ) & $560 \mathrm{mV}$ & $100 \%$ \\
\hline & $560 \mathrm{mV}$ & $51 \%$ \\
\cline { 2 - 3 } $\mathrm{NiS} /$ Tri-chloro Iron ( III) & $600 \mathrm{mV}$ & $65 \%$ \\
\cline { 2 - 3 } & $650 \mathrm{mV}$ & $97 \%$ \\
\cline { 2 - 3 } & $700 \mathrm{mV}$ & $110 \%$ \\
\hline
\end{tabular}

*ratio vs $\mathrm{Cu}$ medium at $560 \mathrm{mV}$ as $100 \%$

Table 4 Elements extraction ratio of MS chlorine leaching in the case of ORP difference. $(4 \mathrm{~h})$

\begin{tabular}{ccccc}
\hline \multirow{2}{*}{ Chlorine-leaching reaction } & \multirow{2}{*}{ ORP } & \multicolumn{3}{c}{ Leaching ratio } \\
\cline { 3 - 5 } & & $\mathrm{Ni}$ & $\mathrm{Co}$ & $\mathrm{S}$ * \\
\hline NiS / Di-chloro Copper ( II ) & $560 \mathrm{mV}$ & 97.5 & 89.2 & 8.4 \\
\hline \multirow{2}{*}{ NiS / Tri-chloro Iron ( III) } & $560 \mathrm{mV}$ & 47.3 & 48.0 & 4.2 \\
\cline { 2 - 5 } & $600 \mathrm{mV}$ & 51.0 & 53.0 & 4.5 \\
\cline { 2 - 5 } & $650 \mathrm{mV}$ & 54.7 & 61.7 & 6.8 \\
\cline { 2 - 5 } & $700 \mathrm{mV}$ & 63.8 & 66.6 & 8.5
\end{tabular}

* $\mathrm{SO}_{4}{ }^{2-}($ produced by MS oxidation $) /$ total $\mathrm{S}$ in MS
$560 \mathrm{mV}$ および $600 \mathrm{mV}$ 時では，それぞれ制御 ORP 到達後塩 素ガス吹き込み速度 $0.8 \times 10^{-5} \mathrm{~mol} / \mathrm{s}, 0.9 \times 10^{-5} \mathrm{~mol} / \mathrm{s}$ に対応 した速度となっており $1 / 4$ 程度まで低下している。すなわち, 反応に寄与している酸化剂量が不足していることになる。こ の結果は塩素ガスの供給を伴わない塩化鉄 $($ III ) , 塩化銅 ( II ) の酸化剤の反応速度が塩化鉄 $($ III ) の方が僅かに高速であった こととも矛盾しない.

一方, 制御 ORP の上昇に伴い，前出の式 (6) 反応によって 硫黄酸化率が増加するとともに, $650 \mathrm{mV}$ 以上で塩素ガスと して系外へロスしている. Fig. 7 に塩化鉄媒体を用いたとき の $560 \mathrm{mV}$ および $700 \mathrm{mV}$ 反応の浸出残椬の SEM 像を示す. 浸出速度が低下する $700 \mathrm{mV}$ 反応の残椬表面は最表面に大き な隙間なく板のように平らに連なり緻密な元素硫黄表面を有 しているのに対して, $560 \mathrm{mV}$ では最表面に表面積の大きな微 細構造を有する隙間を有していることが分かる。すなわち, 式(4)から式 (6)の反応以外に, 式(8),（9)に示す塩素ガ スが直接 MS または硫黄と残椬表面で反応が進むことにより 表面層が物質拡散を抑制する形態に変化し，反応を抑制して いると言える.

$$
\begin{gathered}
\mathrm{NiS}+4 \mathrm{H}_{2} \mathrm{O}+4 \mathrm{Cl}_{2}=\mathrm{NiSO}_{4}+8 \mathrm{HCl} \\
\mathrm{S}+4 \mathrm{H}_{2} \mathrm{O}+3 \mathrm{Cl}_{2}=\mathrm{H}_{2} \mathrm{SO}_{4}+6 \mathrm{HCl}
\end{gathered}
$$

この結果から考察すると, $650 \mathrm{mV}$ 以上の反応では(1)まず 塩素ガスが媒体を酸化, (2)過剩分の塩素ガスが MS または生 成された元素硫黄表面で媒体を介さず直接反応, (3)浸出残椬

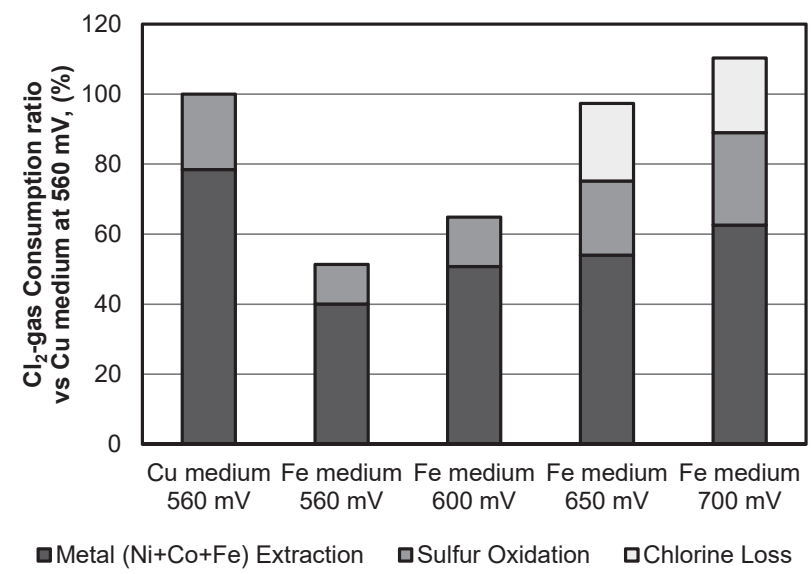

Fig. 6 Breakdown of Chlorine gas consumption in MS chlorine leaching using iron and copper chloride at various ORP.
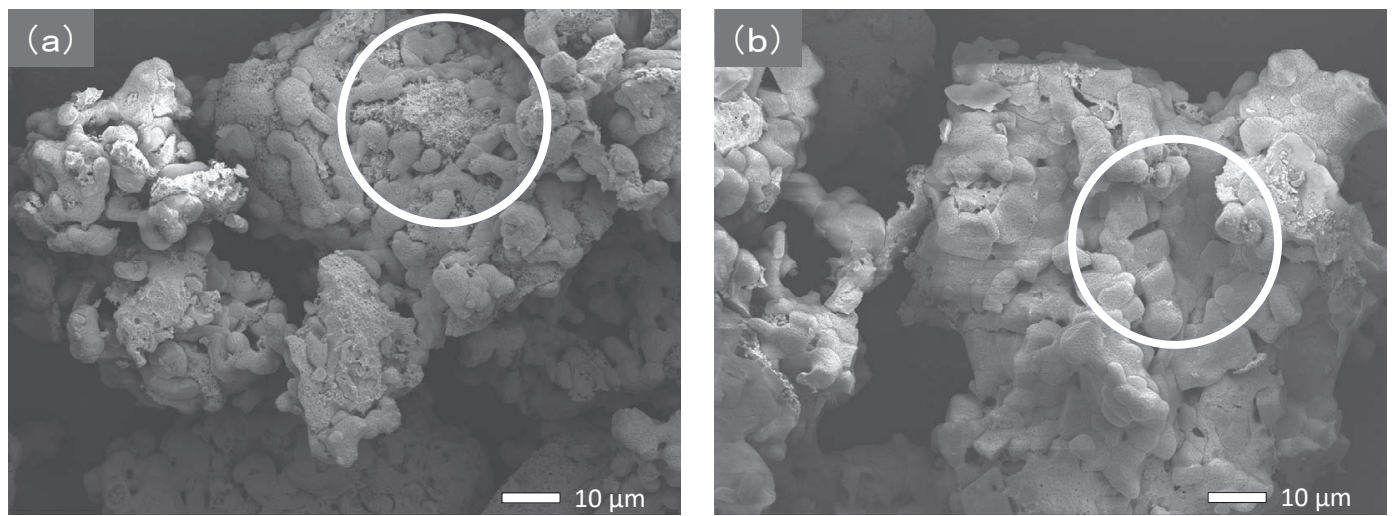

Fig. 7 SEM images of the surface of leach residues with the use of $\mathrm{FeCl}_{3}$. ORP; (a) $560 \mathrm{mV}$, (b) $700 \mathrm{mV}$. 
表面に物質拡散を抑制する層を形成し，ニッケルの浸出反応 を抑制という機構が働き，ほとんどが媒体を介する生成層内 拡散による塩化銅の場合と異なる反応が生じていると考えら れる。

これらの結果から MS の塩素浸出工程の効率向上を目的と した塩化鉄媒体の塩化銅媒体への代替は以下の点で困難と判 断される.

(1)塩化鉄 $($ III ) と塩化銅 (II )の酸化剤のニッケル浸出速度は 酸化還元対の酸化還元電位が高い塩化鉄 (III) の方が高速であ るが，塩化銅を媒体とする塩素浸出において，効果的な 600 $\mathrm{mV}$ の反応 ORP 条件では，塩化鉄の酸化剂イオン種である $\left[\mathrm{FeCl}_{2}{ }^{+}\right]$, が塩化銅の酸化剂イオン種 $\left[\mathrm{CuCl}_{2}\right]$ との比較で不 足するため, 塩化銅媒体と同等の反応速度は得られない.

(2)制御 ORP $650 \mathrm{mV}$ 以上では反応機構が変化し, 反応の一 部が媒体を経由せずに MS または元素硫黄と塩素ガスとの直 接反応となるため, ニッケル浸出反応速度が上昇しない.

\section{4. 結 言}

MS の塩素浸出において同じ硫化物のであるニッケルマッ トと比して劣る化学反応性を向上させる手段として, 塩素浸 出の塩素浸出媒体として従来の塩化銅の代わりに塩化鉄を利 用する方法を比較検証した。その結果, MS の塩素浸出に対 する塩化鉄利用の見地から以下の結論を得た。

(1) MS の塩素浸出における酸化剂である塩化鉄 (III)の ニッケル選択浸出機構は塩化銅 ( II ) 同様, Janderの式との相 関性が高く，生成層内拡散律速と判断できる.

(2) 塩化銅を媒体とする塩素浸出において，高いニッケル 浸出率を得られ，かつ硫黄酸化率を抑制できる 530-560 mV の制御 ORP 範囲では塩化銅媒体の場合の $50 \%$ 程度のニッケル 浸出速度しか得られないことを確認した。

(3) ニッケル浸出速度が低い原因の一つは反応制御 ORPが 低いことによる, 生成酸化剂 $\left(\left[\mathrm{FeCl}_{2}{ }^{+}\right]\right)$量の不足であると考
えられる。

（4）制御 ORPの上昇により酸化剂量を増やせるが， $650 \mathrm{mV}$ 以上まで上昇させると反応機構が変化し, 塩化鉄媒体を経由 しない塩素ガスと MS および元素硫黄との直接反応が促進さ れる.この反応により浸出残椬表面に物質拡散を抑制する層 が形成され，ニッケル浸出が抑制されると考えられる。この ため生成層内拡散により反応が進む塩化銅媒体への代替は困 難である。

最後に本研究を報告するに当ってご助言を頂いた東北大学 多元物質研究所の福山博之教授，大塚誠准教授に感謝の意を 表します。

文献

1) S. Makino, N. Kemori, N. Matsumoto and S. Matsumoto: Proc. The NICKRL-COBALT 97 International Symposium, (27 $7^{\text {th }}$ Annual Hydrometallurgical Meeting of CIM, Sudbury, Ontario, 1997) vol. 1, pp. 123-135.

2) H. Kobayashi, H. Shoji, S. Asano and M. Imamura: J. Japan Inst. Metals 80(2016) 713-718.

3) M. Imamura: The study of Hydrometallurgical process of nickel matte, Doctor TOHOKU UNIVERSITY, 1997, ph. D. in metal engineering.

4) M. Pourbaix: Atlas of Electrochemical Equilibria in Aqueous Solutions, (Pergamon Press, London, 1966).

5) L. Gordon and J. M. Demarthe: Hydrometallurgical treatment process for extracting constituent metal values from ferro-nickel U. S. Patent 4,016,054. 1977-04-05.

6) N. Tsuchida, Y. Ozaki, O. Nakai and H. Kobayashi: Proc. International Laterite Nickel Symposium, (TMS Annual Meeting, Charlotte, NC, 2004) pp. 151-160.

7) H. Kobayashi and M: Imamura: Proc. Hydrometallurgy of Nickel and Cobalt 2009 International Symposium, (39 $9^{\text {th }}$ Annual Hydrometallurgical Meeting of CIM, Sudbury, Ontario, 2009) pp. 27-37.

8) Y Meng and A. J. Bard: Anal. Chem. 87 (2015) 3498-3504.

9) H. K. Lin, X. J. Wu and P. J. Rao: JOM 43(1991) 60-65.

10) R. Winand: Hydrometallurgy, 27 (1991) 285-316.

11) L. G. Sillen and A. E. Martell: Stability Constants of metal ion complexes, (Chemical Society, London, 1964). 